\title{
Solid Oxide Fuel Cell - Gas Turbine Hybrid Power Plant
}

\author{
M. Henke, C. Willich, M. Steilen, J. Kallo, K. A. Friedrich
}

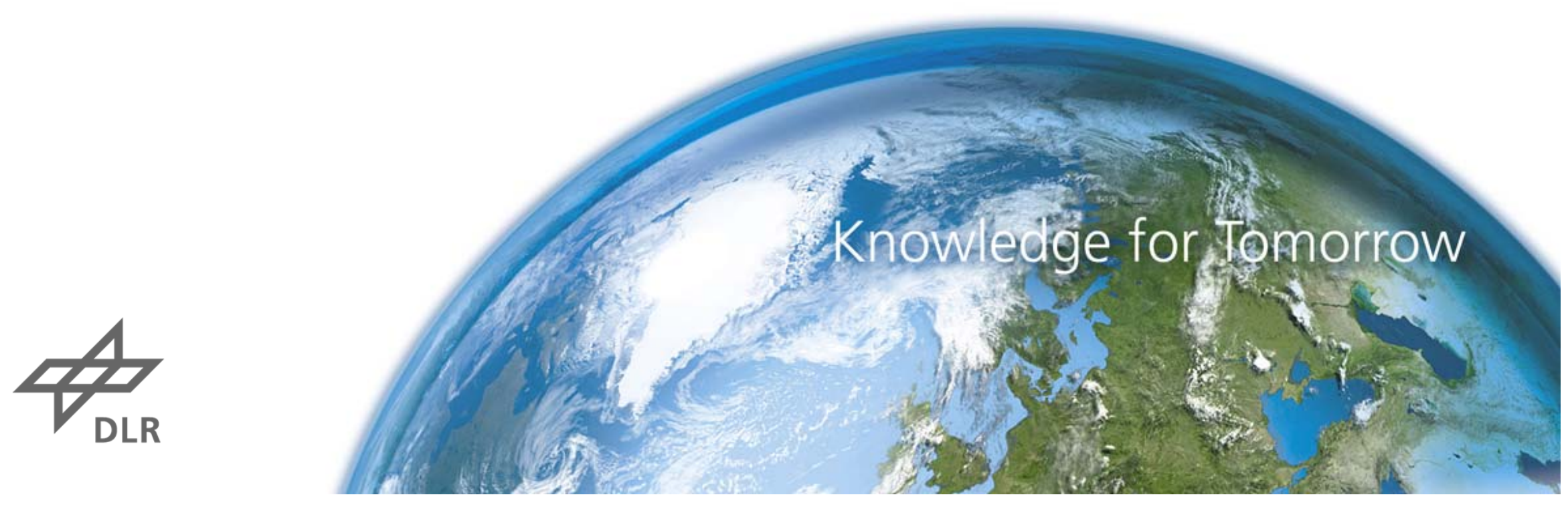




\section{Motivation: Hybrid Power Plant}

- Combination of SOFC and gas turbine

- High electrical efficiency of 50-70 \% (LHV)

- SOFC pressure determined by gas turbine

- Aim to build and operate a system with an electrical power output of about $30 \mathrm{~kW}$

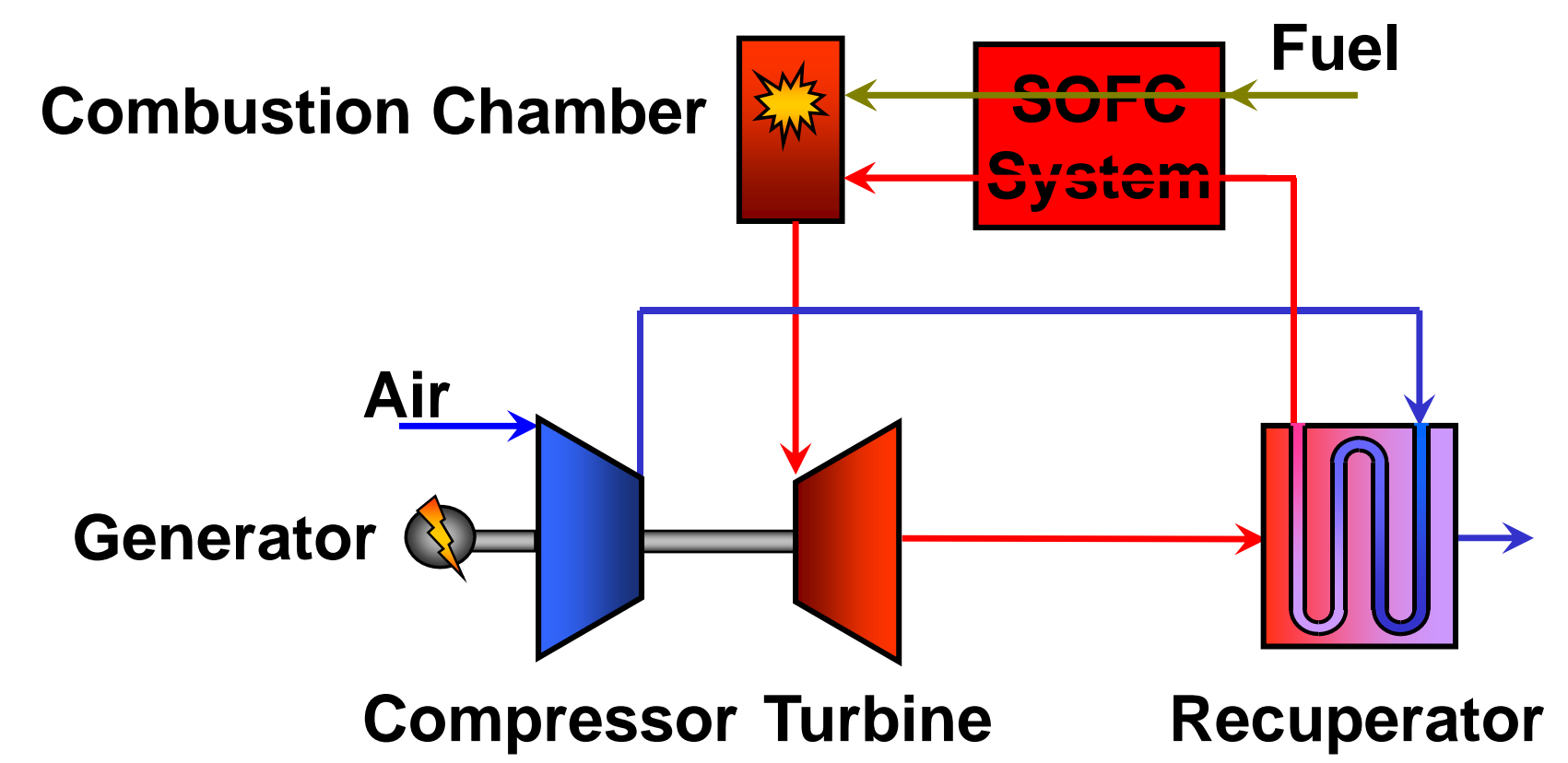




\section{Hybrid Power Plant: Efficiency}

- SOFC

$\eta_{\mathrm{el}}=50 \mathrm{~kW} / 100 \mathrm{~kW}=50 \%$

- Gas turbine

$\eta_{\mathrm{el}}=10 \mathrm{~kW} / 50 \mathrm{~kW}=20 \%$

- Overall system

$\eta_{\mathrm{el}}=60 \mathrm{~kW} / 100 \mathrm{~kW}=60 \%$
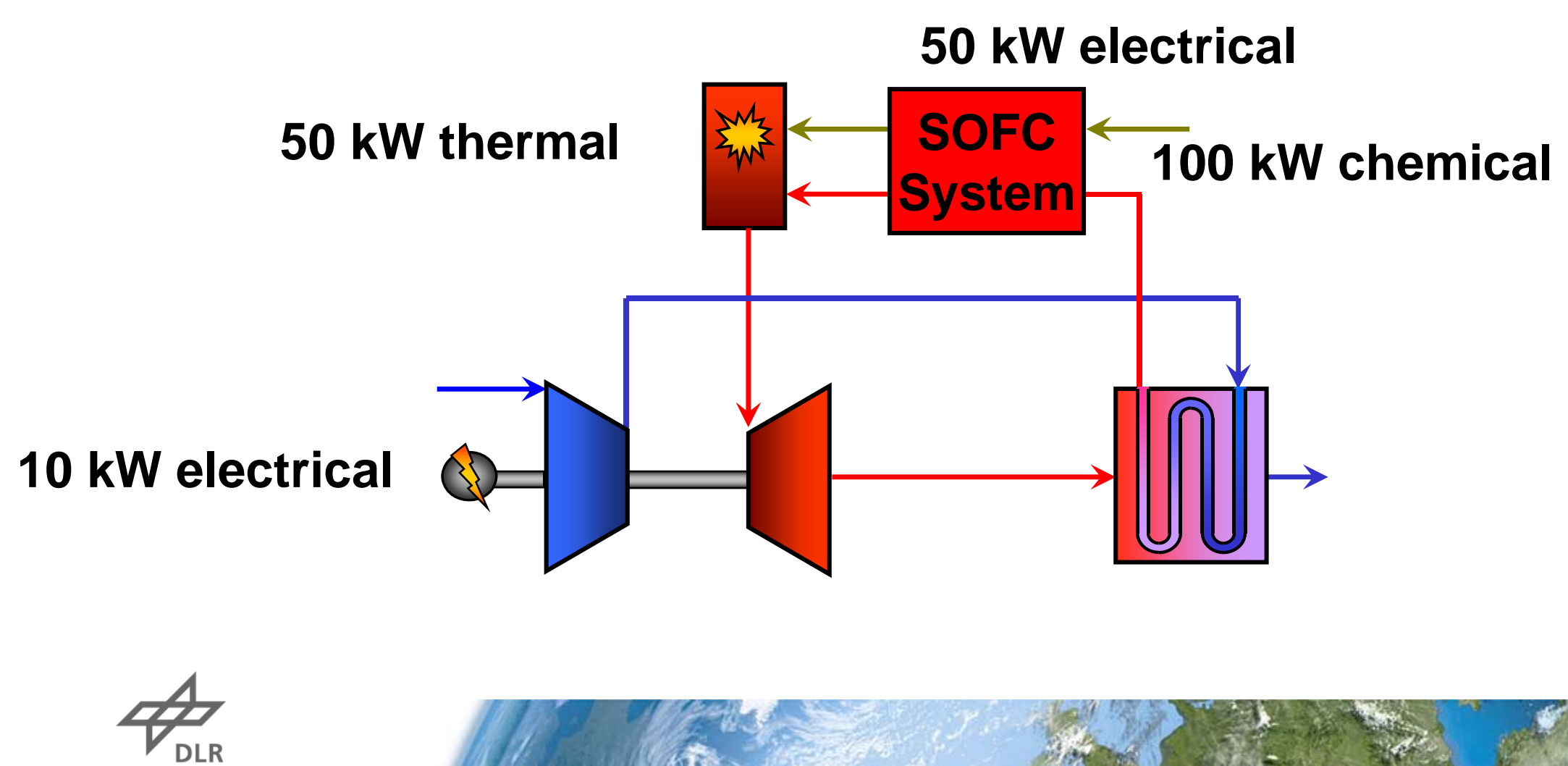


\section{Operating Strategy of Hybrid Power Plant}

Aim:

- High electrical efficiency over wide power range

- Simple system layout

Operating Strategy:

- System control similar to gas turbine control

- Variable turbine speed

- Variable SOFC temperature and electrical power output

Scientific Approach:

- Matching of SOFC and gas turbine

- Sensitivity analysis

- Performance analysis
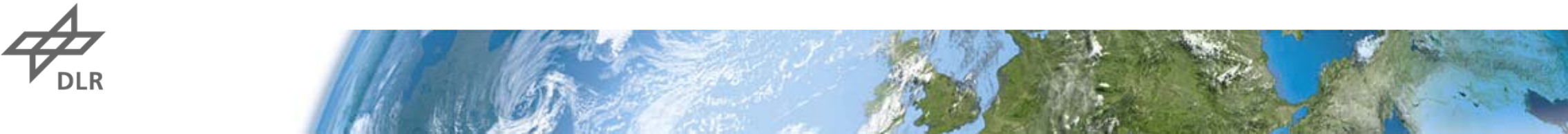


\section{Schematic of Hybrid Power Plant Model}

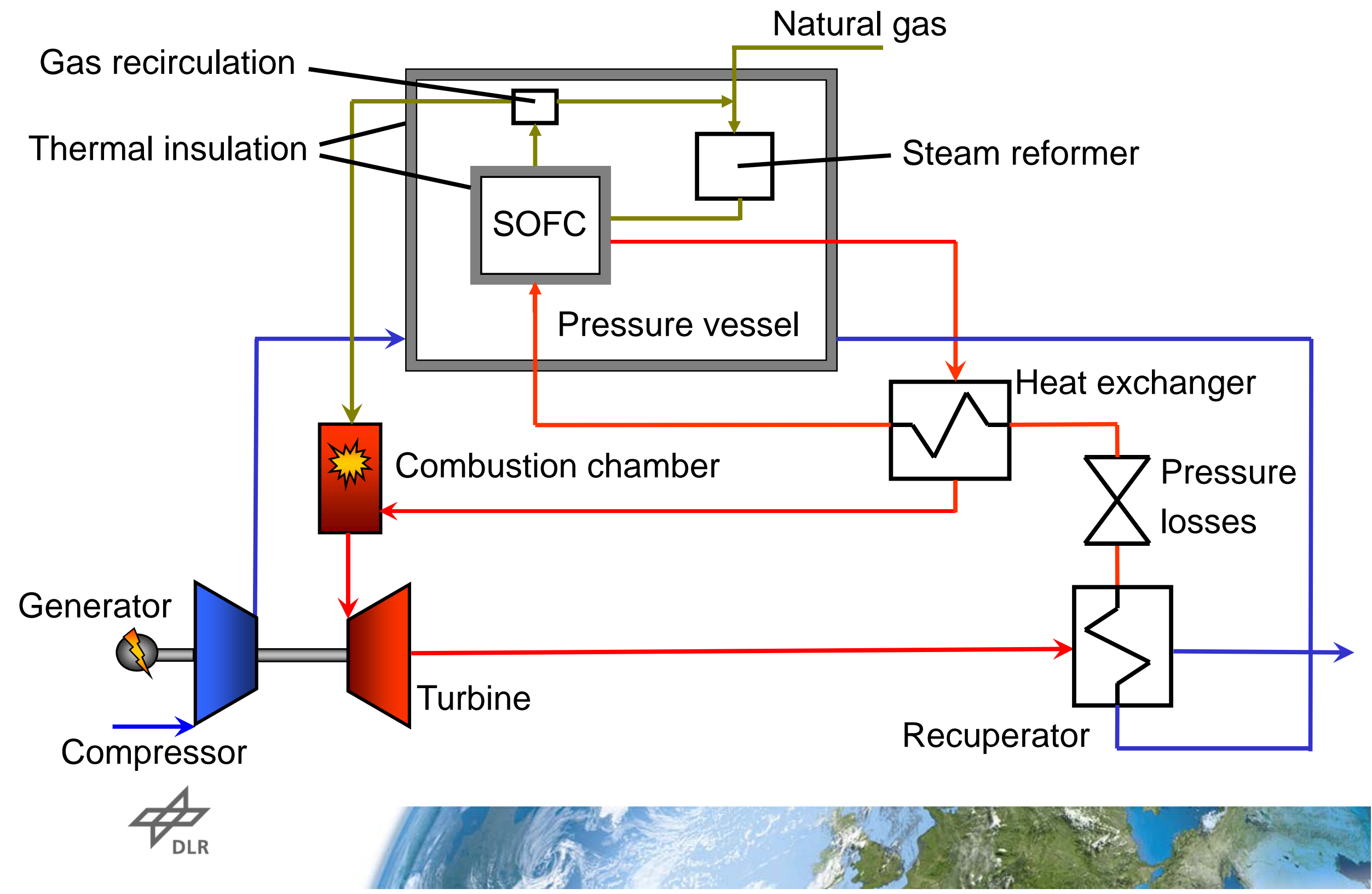




\section{SOFC Model Validation}
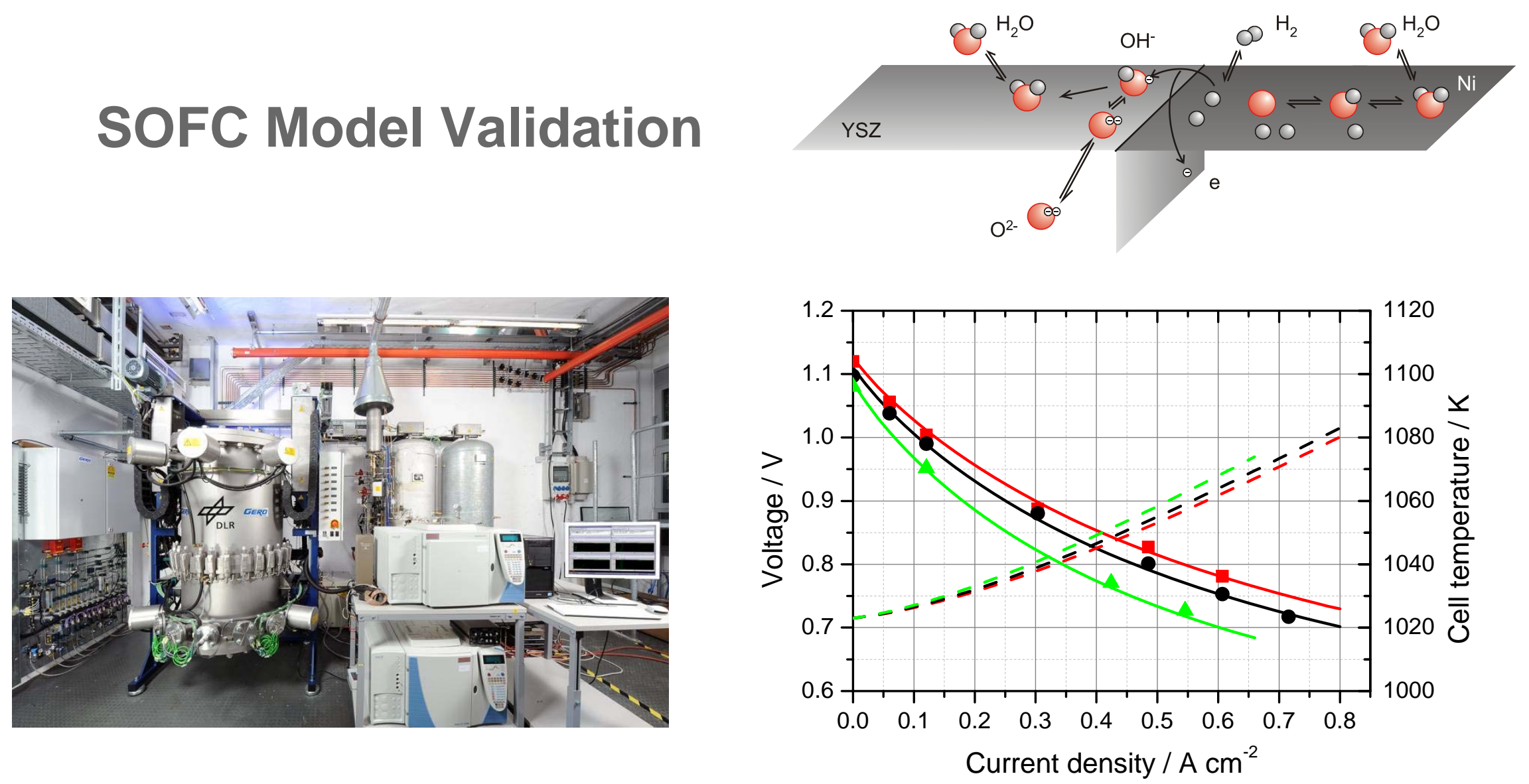

Experimental validation of detailed stack model

Pressure variation:

- Electrochemistry

8 bar

- Temperature distribution

4 bar

1.35 bar
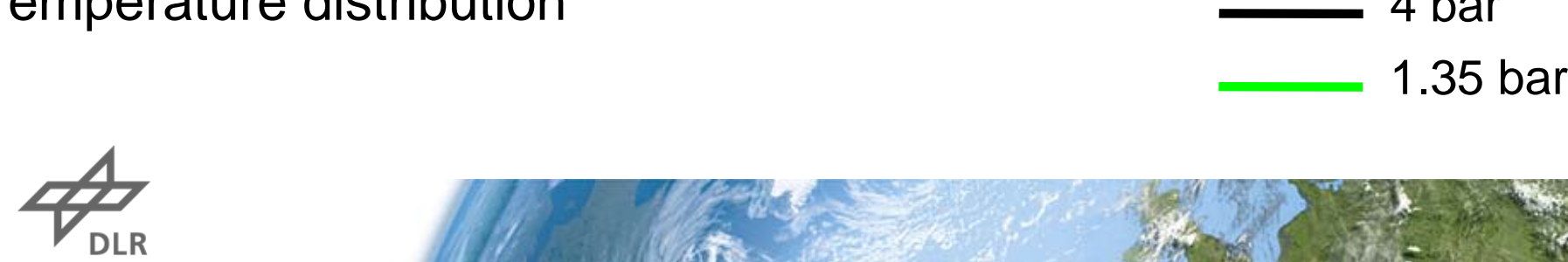


\section{Sensitivity Analysis}

Reference conditions:

- 400 stacks with 60 cells each

- 500 kW electrical SOFC power (DC)

- $75 \%$ anode gas recirculation

- $40 \%$ efficiency of cathode heat exchanger

- $10 \mathrm{~kW}$ losses of thermal energy from pressure vessel

- 150 mbar pressure loss of SOFC system

- 65000 rpm turbine speed

- 0.3 m stack insulation thickness

Separate variation of each parameter within realistic limits

Analyzed data:

- SOFC voltage

- SOFC temperature

- Electrical efficiency 


\section{Cell Voltage}

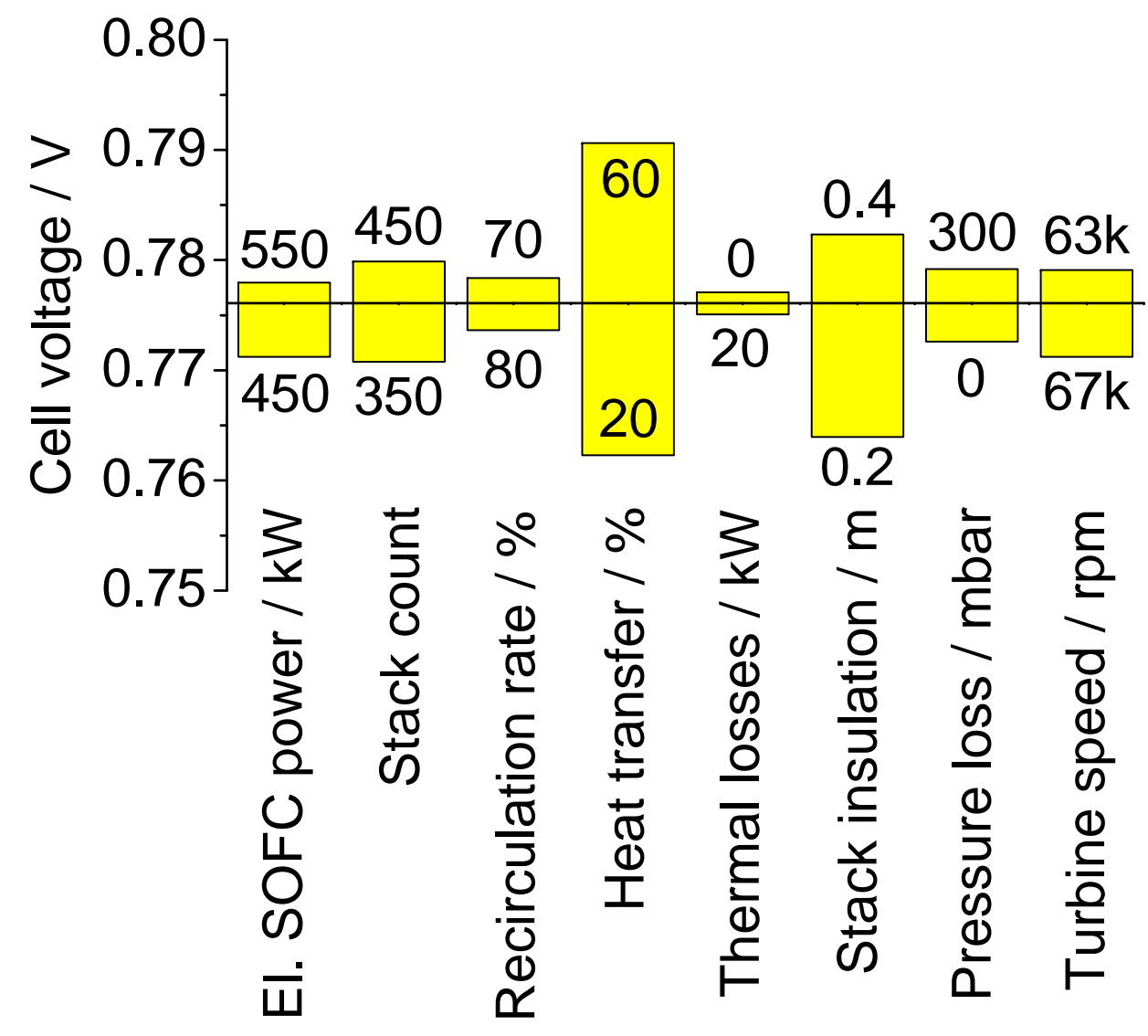

- Cell voltage is important parameter concerning degradation $(>0.7 \mathrm{~V})$

- Strongest influence of heat transfer and stack insulation (temperature effect)

- Only very small overall changes

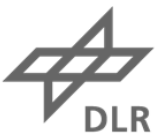




\section{Cell Temperature}

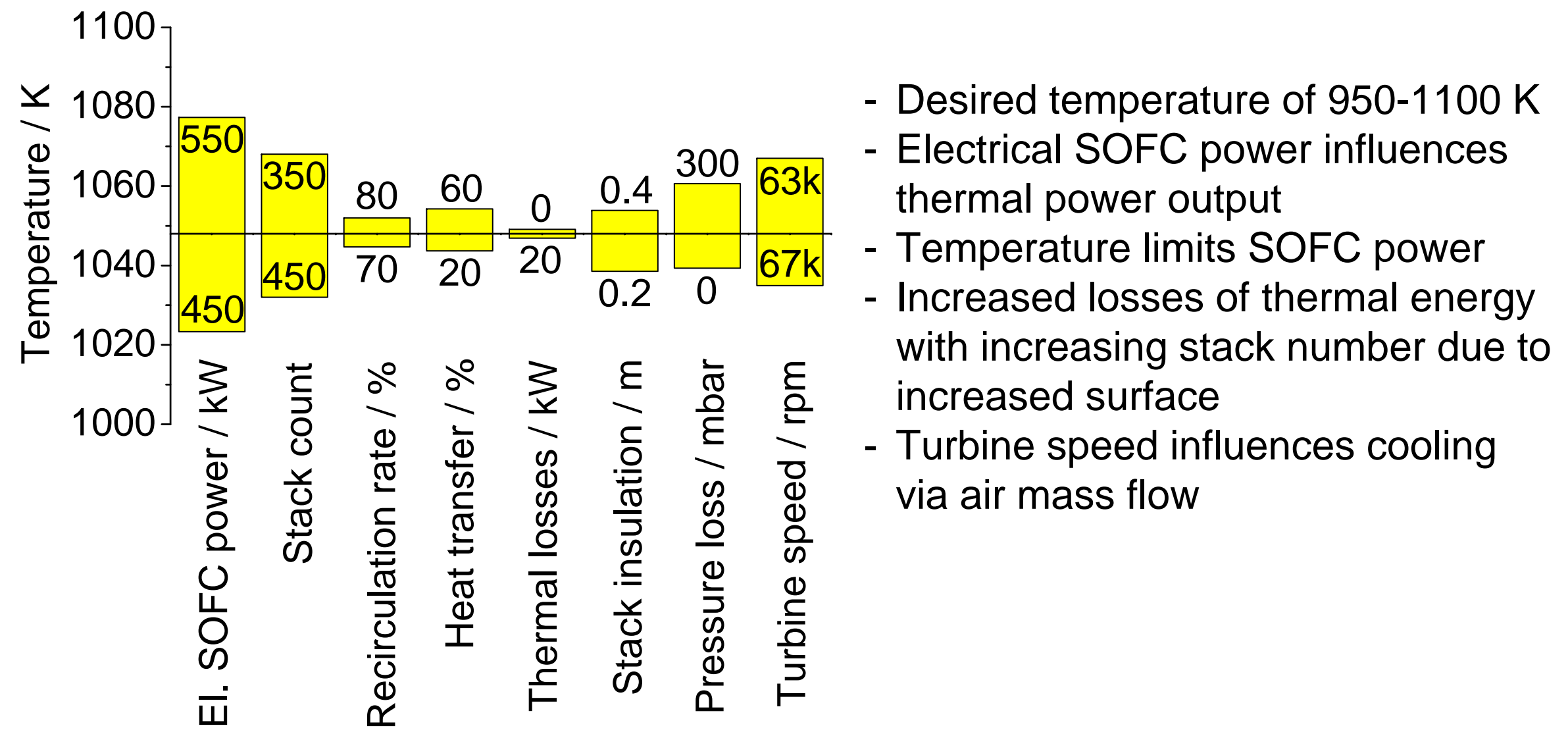




\section{System Efficiency}

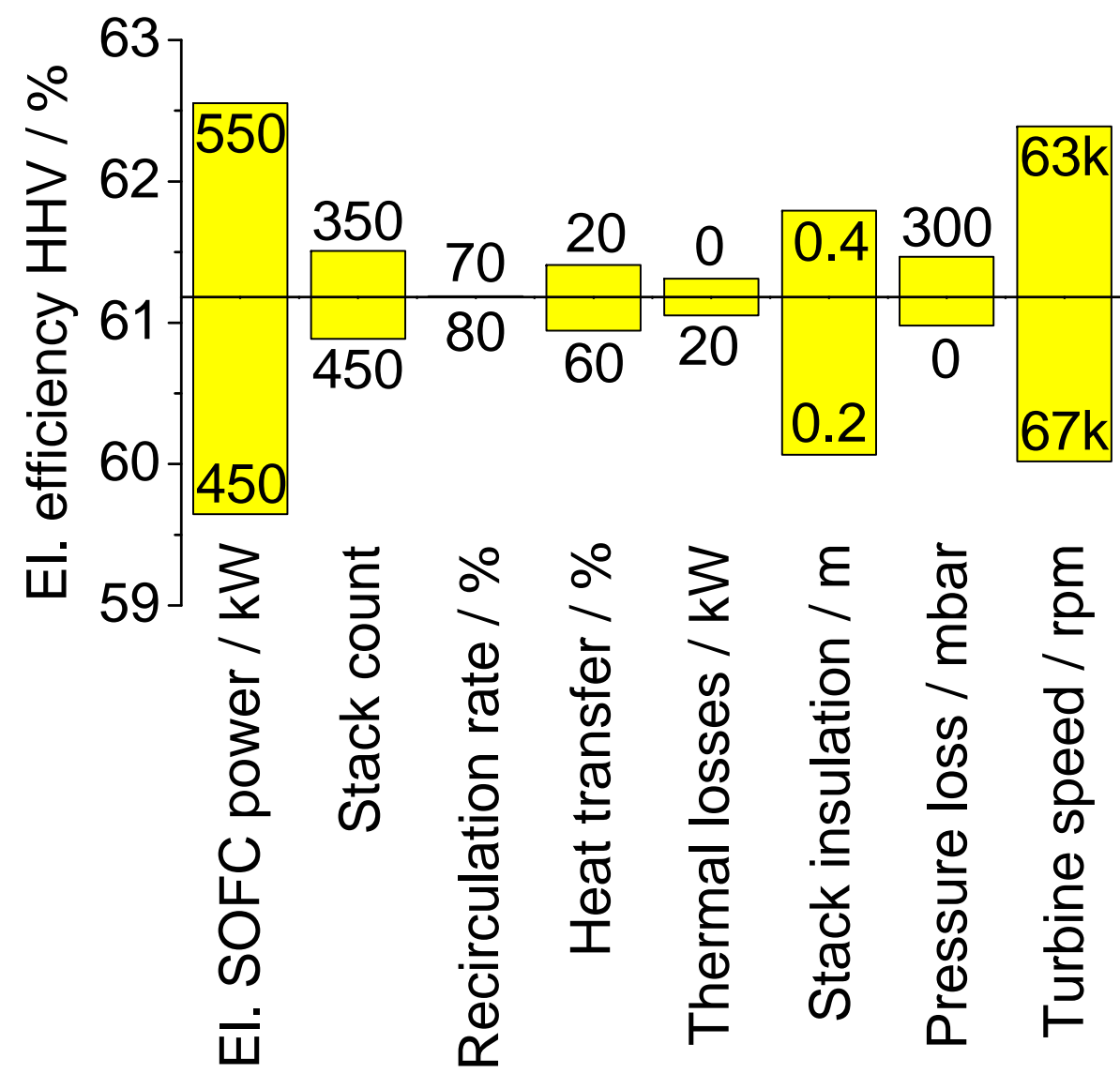

- Power ratio SOFC:GT is key parameter for high efficiency

- Non-linear influence of stack insulation

- Thermal losses of pressure vessel can be compensated

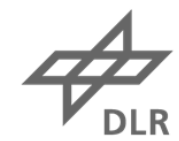




\section{Power Range of Hybrid Power Plant}

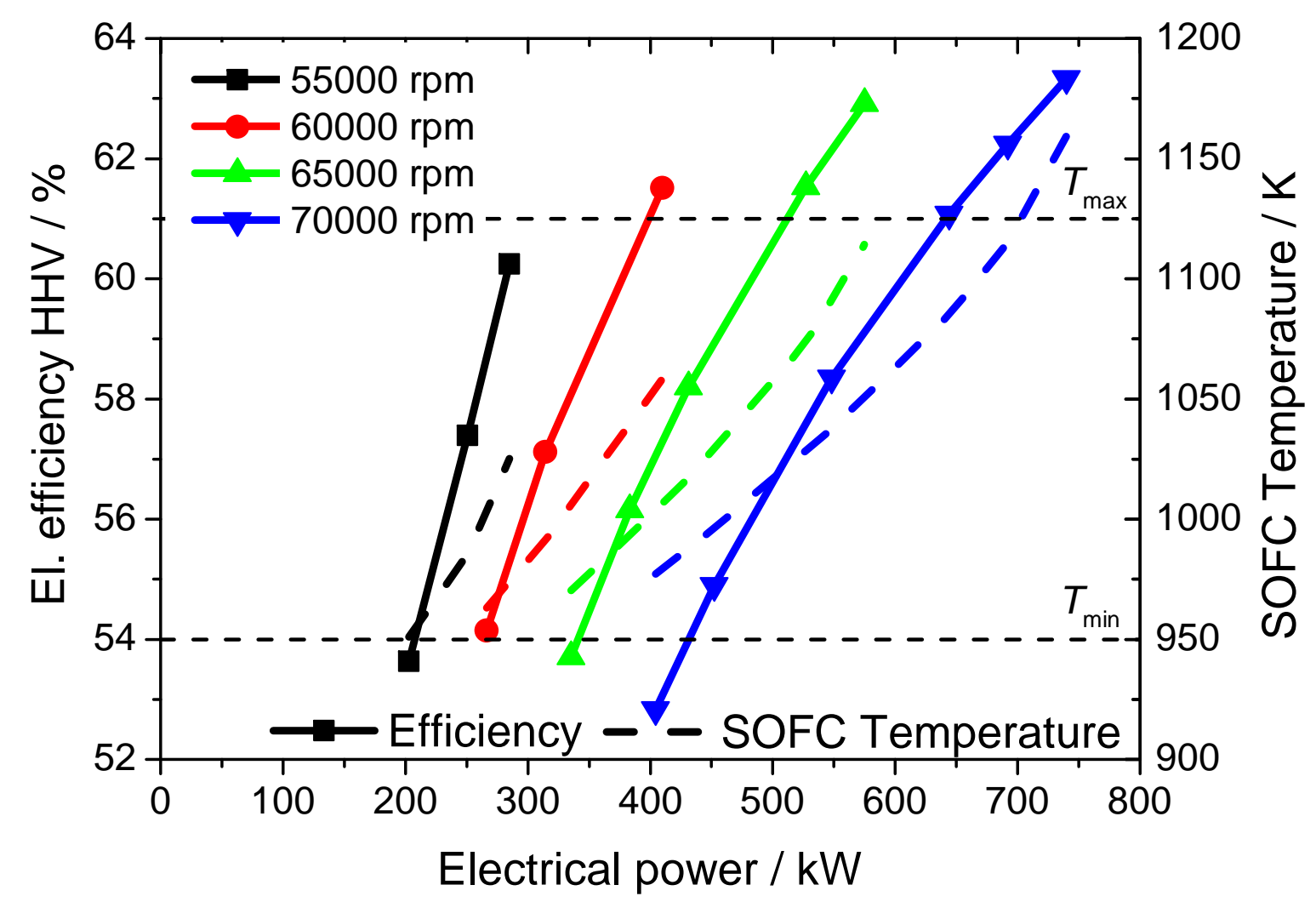

- Fixed system components

- Variable turbine speed

- Variable SOFC electrical power

- Large power range from $200 \mathrm{~kW}$ to $700 \mathrm{~kW}$

- Very high electrical efficiency of $60 \%$ from $300 \mathrm{~kW}$ to $700 \mathrm{~kW}$
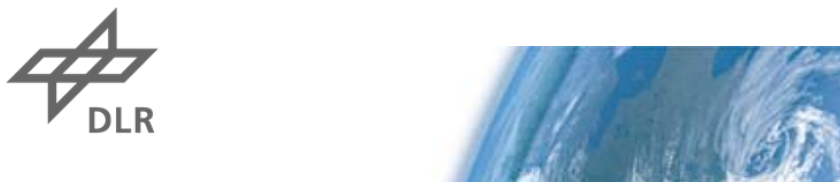


\section{Conclusions}

- Operating strategy offers high electrical efficiency over large power range

- Power ratio of SOFC:GT is crucial parameter for high efficiency

- Optimized thermal insulation can improve efficiency

- SOFC temperature limits operating range of power plant

Acknowledgements

- German Aerospace Center (DLR)

- Federal Ministry of Economics and Technology (BMWi) \& EnBW

(FKZ 03ET2018) 